\title{
Malignant Neoplasm of the Upper Third of the Esophagus
}

National Cancer Institute

\section{Source}

National Cancer Institute. Malignant Neoplasm of the Upper Third of the Esophagus. NCI

Thesaurus. Code C3533.

A primary or metastatic malignant neoplasm involving the upper third segment of the esophagus. 